\title{
A Theory of Optimal Green Defaults
}

\author{
Georg Meran ${ }^{1, *}$ and Reimund Schwarze ${ }^{2}$ (1) \\ 1 Faculty of Economics and Management, Berlin University of Technology, 10623 Berlin, Germany \\ 2 Department of Economics, Helmholtz Centre for Environmental Research (UFZ), 04318 Leipzig, Germany; \\ reimund.schwarze@ufz.de \\ * Correspondence: g.meran@tu-berlin.de; Tel.: +49-30-314-25263
}

Received: 10 July 2018; Accepted: 3 August 2018; Published: 16 August 2018

check for updates

\begin{abstract}
This paper develops an analytical framework for studying the Baumol-Oates efficiency of traditional single instrument abatement policies vis-à-vis green defaults in the face of price inertia and passive choice by subpopulations. In this special case of behavioural heterogeneity, command and control approaches can outperform price-based instruments while pure tax/subsidy schemes need to be adjusted in order to achieve politically desired levels of abatement. We also prove that choice-preserving nudges are superior to any single-instrument policy in this case. An average marginal abatement cost rule is developed to optimize the green defaults and traditional policies of standards and prices under different degrees of market rigidity.
\end{abstract}

Keywords: nudge; policy mix; behavioural heterogeneity; environmental taxes and subsidies

JEL Classification: D91; H21; H23; L51; Q52; Q58

\section{Introduction}

In recent years, results of behavioral economics have entered the process of developing control instruments in various policy areas. The Joint Research Centre, the European Commission's in-house science service (J. Lourenço et al. [1]), provides a compact overview of the role played by behavioral insights in the different policy areas of the member states. The European Economic and Social Committee has called for an increased inclusion of nudges as a complementary means to policy instruments (EESC [2]). (See also Piniewski et al. [3], Oullier and Sauneron [4], Council of the Environment and Infrastructure [5] and OECD [6]).) The increased interest in policy instruments based on behavioral results is certainly due to the fact that many instruments based solely on economic incentives do not have the expected effectiveness.

Behavioural economists have observed a great number of seemingly irrational human behaviors, which cannot be explained by conventional economic theory (Carlsson and Johansson-Stenman [7]). One such finding is the prevalence of various forms of passive/no choice behavior resulting in the 'stickiness of defaults' (Madrian and Shea [8]; Carroll et al. [9]). These behavioral traits are often observed in subpopulations such as elderly people or youngsters, but are also evident in comparisons of small and large firms (e.g., Revell and Blackburn [10] and Ellison [11]). This gives rise to the profound problem of behavioral heterogeneity in economic policy. The notion that individuals, firms and corporations respond differently to economic stimuli and default rules has obvious consequences for the effectiveness and optimality of regulation. The long-standing debate about 'Quantities versus Prices' (Weitzman [12]) is just one of the candidates potentially affected by this; others are theories of enforcement (Malik [13]) and rules of liability and contract law (Jolls et al. [14]).

A more recent policy approach within behavioral economics is nudging (Thaler and Sunstein [15] and Schubert [16]). A nudge, according to Thaler and Sunstein, is "any aspect of the choice architecture 
that alters people's behavior in a predictable way without forbidding any options or significantly changing their economic incentives." In their classic "cafeteria example" (Thaler and Sunstein [15], p. 6.) a cafeteria owner arranges the food she has on offer in such a way that healthy foods are displayed at the front to stimulate customers to buy and eat more healthfully. Other famous examples of nudges are smaller plates in canteens to reduce calory intake, or technical and contractual defaults such as double page printer settings and pre-defined retirement plans (from opt-in to opt-out). By definition, a nudge does not change the set of choices, and so any attentive and otherwise unbounded, rational economic agent will not be affected by it. There are a variety of nudges that focus on different motivational contexts (Michalek et al. [17]). Here, for example, eco-labels, which address a green self-image, are to be mentioned in the environmental policy context. Green nudges also point to the social context in which decisions are made. These nudges utilize peer comparisons. Allcott [18] reports of a field experiment where customers should be induced to save energy by means of a home energy report containing their consumption data in comparison to their neighborhood. There are also green nudges that are designed as green defaults. Green defaults come into play when people don't actively choose but, instead, follow the default set. Schubert [16] points to various psychological factors for the lack of active choice. There are various psychological factors for passive choice. These include loss aversion, inertia and confidence in the institutions that set the default.

The use of nudges by social planners is assumed to improve people's welfare; as such, it has been viewed as a form of paternalism. Indeed, it has been coined "libertarian paternalism" (Sunstein and Thaler [19]) or, in the language of behavioural heterogeneity, "asymmetric paternalism", as it will only affect subgroups with certain flaws in their decision-making (Camerer et al. [20]; Hausman and Welch [21], p. 126). Thaler and Sunstein recommend that the regulator should influence consumers' choices in a way that make consumers better off, "as judged by themselves" (Thaler and Sunstein [15], p. 5). However, as Amir and Lobel ([22]) emphasize, nudges are neither libertarian, nor paternalistic but a form of new governance that integrates "design with incentives, collaboration with control, information with data mining and data minding, reflexive regulation with monitoring and enforcement." (ibid., p. 2117). Paternalistic nudges that are not construed by externalities or third-party effects but rather aim "to help the person whose behaviour is altered by nudges" (Loewenstein and Haisley [23]) are suffering from the same basic knowledge problems and lacking normative foundations as any hard paternalistic policy such as prohibition. In this regard, the difference between soft and hard paternalism is "one of degree, not one of principle" (Schnellenbach [24]).

Another ethical issue relates to the potentially manipulative nature of nudges (Croson and Treich [25]). Hansen and Jespersen [26] differentiate between a non-transparent manipulation of choice and behaviour by means of nudges and a transparent facilitation of behaviour ("empowerment nudges"). While this juxtaposition is stylized (and more work should be done on clarifying the categories), there seems to be a consensus in the literature that technical 'green defaults' (e.g., preset double-sided print options) are non-manipulative and ethically defensible (Thaler and Sunstein [15]).

These rather complex ethical issues do not arise in this paper because we refer to the well-established Baumol-Oates approach of politically defined standards and efficiency-enhancing prices (Baumol and Oates [27]), while our concern is non-manipulative 'green defaults'. The most closely related paper to this one is Allcott et al. [28]. It models the choice of energy efficient durables in the face of myopia (present bias) and over- or undervaluation of energy savings of different products (biased belief) as well as inattention to energy cost savings. The authors frame these different "tastes" for energy savings in a model of heterogeneous consumers and derive the welfare-enhancing property of a second-best policy mix of taxes below marginal damages combined with a larger subsidy for energy efficient products. Quantity-based instruments are not considered and, consequently, also not policy mixes of green defaults as the regulation itself is not standard oriented but utility maximizing with an assumed damage function. This paper deals with the effects of behavioural heterogeneity on standard-oriented environmental policy. There are two types of actors (firms): decision makers that don't engage in active choice but simply follow given defaults and actors that independently calculate 
costs and benefits of their decisions. We assume that a subset of firms suffers from organizational inertia as well established in the theory of organizational rigidities (Kaplan and Henderson [29]). Stickiness of firm behavior may result from the management being biased or can also be explained by institutionalized cognitive frames and motivational factors in an organization. (We also could easily apply this analysis to household emitters with different costs of abatement and would not expect fundamentally different modeling results.) Departing from the traditional taxes-versus-quotas debate in environmental economics, we demonstrate that direct regulation by means of command-and-control can outperform price-based policies under certain circumstances, and that the design of environmental subsidies and taxes as policy instruments needs to reflect behavioural heterogeneity. Moreover, we make the economic case for using green defaults as a choice-preserving policy mix of regulatory standards and price-based incentives, which lead to superior results compared to any single-instrument policy in populations that display behavioural heterogeneity.

\section{The Model}

In this paper, we consider emitting firms of $\mathrm{K}$ different technologies. These technologies are ordered with respect to abatement costs . $C_{k}(a), k=1,2, \ldots, K$ where $a$ is abatement. The technologies exhibit the following properties:

$$
\begin{array}{cc}
C_{1}(a)<C_{2}(a)<\cdots<C_{K}(a), & \forall a>0, \\
C_{1}^{\prime}(a)<C_{2}^{\prime}(a)<\cdots<C_{K}^{\prime}(a), & \forall a>0, \\
C_{k}(0)=C_{k}^{\prime}(0)=0 . &
\end{array}
$$

To keep the analysis simple, we assume a quadratic abatement cost function

$$
C_{k}(a)=\frac{b_{k}}{2} a^{2}, \quad k=\{1,2, \cdots, K\}, \quad b_{1}<b_{2}<\cdots<b_{K},
$$

which satisfies Equation (1).

Finally, we assume that there are $N_{k}, k=\{1,2, \cdots, K\}$ emitters within each technology class. Hence, the total sum of emitters amounts to

$$
N=\sum_{k=1}^{K} N_{k}
$$

Environmental policy enters into the model by utilizing the price-standard approach introduced by Baumol and Oates [27]. The public authority introduces an emission reduction requirement. We start from unrestricted emissions $\left\{e_{1}^{\max }, e_{2}^{\max }, \cdots, e_{K}^{\max }\right\}$ where $e_{k}^{\max }$ are emissions from technology $k$ unrestriced by policy measures. We could also imagine that these amounts refer to historic emissions from a base year.

The authority fixes a minimum total reduction obligation for all emitting firms such that

$$
\sum_{k=1}^{K} \sum_{i=1}^{N_{K}} a_{i k} \geq \gamma E=\gamma \sum_{k=1}^{K} N_{k} e_{k}^{\max }, \quad 0<\gamma<1
$$

The efficient allocation of abatement across emitters can be achieved by minimizing total abatement costs, i.e.,

$$
\sum_{k=1}^{K} \sum_{i=1}^{N_{K}} C_{k}\left(a_{i k}\right)
$$

subject to Equation (4).

From the first order conditions, we know that 


$$
C_{k}^{\prime}\left(a_{i k}\right)=\lambda, \quad i=\left\{1,2, \cdots, N_{k}\right\}, k=\{1,2, \cdots, K\},
$$

where $\lambda$ is the Lagrangean.

Since the abatement cost functions are the same within each technology class, we have

$$
a_{i k}=a_{k}, \quad i=\left\{1,2, \cdots, N_{k}\right\}, k=\{1,2, \cdots, K\} .
$$

The optimal allocation of abatement effort $\mathbf{a}^{*}=\left\{a_{1}^{*}, a_{2}^{*}, \cdots, a_{K}^{*}\right\}$ equates marginal abatement costs to each other.

From the literature, it is well known that a single emission price achieves an efficient allocation of both emissions and abatement levels.

Each emitter of technology class $k$ minimizes her abatemement costs while taking into account the costs of paying for her residual emissions:

$$
\min _{a_{k}}\left[C_{k}\left(a_{k}\right)-\tau\left(a_{k}-\delta e_{k}^{\max }\right)\right] \Rightarrow C_{k}^{\prime}\left(a_{k}\right)=\tau, \quad k=\{1,2, \cdots, K\},
$$

where $\tau$ is a tax rate and $\delta=\{0,1\}$. If $\delta=0$, the environmental authority apply a tax-based approach. If $\delta=1$, the policy maker adopts subsidies to encourage abatement efforts. We could also conceive $\tau$ as the equilibrium price on a certificate market, where $\delta=0$ refers to an auction approach and $\delta=\gamma$ could be described as grandfathering approach. Notice that we have omitted index $i$ because each emitting firm in class $k$ chooses the same abatement level $a_{k}$.

Since each emitter sets her marginal abatement costs equal to the tax rate, an efficient allocation of emissions is achieved (see Equation (6)).

The environmental target is achieved by choosing the tax such that the reduction goal in Equation (4) is satisfied. Hence, $\tau^{*}$ is chosen such that

$$
\sum_{k=1}^{K} N_{k} a_{k}^{\tau^{*}}=\gamma E
$$

where $a_{k}^{\tau}$ solves Equation (8). Alternatively, a command and control approach could be applied. In this case, an overall uniform lower limit of abatement levels $A$ is introduced such that the environmental objective is achieved. To do so, the limit per emitter is set such that

$$
A=\frac{\gamma E}{\sum_{k=1}^{K} N_{k}}
$$

Needless to say, this policy is inefficient if marginal abatement cost functions differ.

\subsection{The Performance of Traditional Policy Instruments under Behavioral Heterogeneity}

In the following, we analyze how the policy instruments reviewed in the previous section affect the allocation of abatement levels when emitters do not always behave rationally across the population, i.e., when they choose their abatement levels so as to minimize their costs. Let us assume that emitting firms behave either rationally with probability $\pi$ or exhibit passive behavior with probability $(1-\pi)$ by neglecting any optimizing efforts (passive choice). We assume that these probabilities are independent of technology type $k$. There is asymmetric information with respect to the behavioral types. The regulator does not know whether the individual emitter is rational or inert. However, the prior distribution is known to the agency. This assumption is in line with the literature on regulation under asymmetric information (see e.g., Laffont et al. [30], e.g., p. 64 ff.). For optimal pollution control under asymmetric information, see. e.g., Dasgupta et al. [31] or Spulber [32]. This assumption is also held in behavioral models. See e.g., Allcott et al. [28]. 
Passive behavior implies that firms or households do not respond to price incentives such as taxes or subsidies. They only comply with whatever measures imposed in the context of a command and control approach out of passivity or a strong anchoring of their choice in given commands. If the policy maker relies only on a price oriented policy (taxes, subsidies, etc.), she will have to take this heterogeneous behavior into account. The same applies to the determination of a single overall abatement level for firms. In addition, the policy has to take into account the stochastic nature of abatement behaviour, which requires the calculation of expected values.

To begin with, let us assume that the policy maker relies exclusively on a tax approach. In this case, the environmental authority needs to calculate expected abatement levels. Take e.g., technology class $k$ consisting of $N_{k}$ emitters. It is a standard tenet of probability theory (see e.g., Mood, Graybill and Boes [33]) that the probability of one out of two events occuring $i$ times $\left(i: 0<i<N_{K}\right)$ is distributed according to the binomial distribution function

$$
\frac{N_{k} !}{\left(N_{k}-i\right) ! i !} \pi^{i}(1-\pi)^{\left(N_{k}-i\right)}
$$

Here, the one event is that emitters behave rationally. The complementary event is that emitters behave passively. Accordingly, this probability applies to $N_{k}-i$ firms behaving passively.

To calculate the expected aggregate abatement level under behavioral heterogeneity, we first have to determine the expected abatement level of each technology class. If a firm behaves rationally, it will choose abatement according to Equation (8), thus leading to a level $a_{k}^{\tau}$. Hence, expected aggregate emissions of class $k$ will be

$$
\sum_{i=0}^{N_{k}}\left(\frac{N_{k} !}{\left(N_{k}-i\right) ! i !} \pi^{i}(1-\pi)^{\left(N_{k}-i\right)} i\right) a_{k}^{\tau}=\pi N_{k} a_{k}^{\tau}
$$

This derivation follows the usual proof in the standard literature. (see e.g., Mood, Graybill and Boes [33], p. 89.)

The same procedure is applied to passively behaving firms that blindly comply with an abatement prescription $A \geq 0$. The probability of this behaviour is $1-\pi$. Hence, the expected abatement level of technology class $k$ is

$$
\sum_{j=0}^{N_{k}}\left(\frac{N_{k} !}{\left(N_{k}-j\right) ! j !}(1-\pi)^{j} \pi^{\left(N_{k}-j\right)} j\right) A=(1-\pi) N_{k} A .
$$

The aggregated expected abatement level of all $k$ technology classes follows directly by adding Equations (12) and (13) across all classes:

$$
\pi \sum_{k=1}^{K} N_{k} a_{k}^{\tau}+(1-\pi) \sum_{k=1}^{K} N_{k} A
$$

It is a straightforward matter to calculate the aggregate expected abatement costs in a similar way:

$$
\begin{array}{r}
A A C=\sum_{k=1}^{K}\left[\sum_{i=0}^{N_{k}}\left(\frac{N_{k} !}{\left(N_{k}-i\right) ! i !} \pi^{i}(1-\pi)^{\left(N_{k}-i\right)} i\right) C_{k}\left(a_{k}^{\tau}\right)\right. \\
\left.+\sum_{j=0}^{N_{k}}\left(\frac{N_{k} !}{\left(N_{k}-j\right) ! j !}(1-\pi)^{j} \pi^{\left(N_{k}-j\right)} j\right) C_{k}(A)\right] \\
=\pi \sum_{k=1}^{K} N_{k} C_{k}\left(a_{k}^{\tau}\right)+(1-\pi) \sum_{k=1}^{K} N_{k} C_{k}(A) .
\end{array}
$$


In the following, we analyse the performance of three traditional policy instruments under the behavioural heterogeneity introduced above.

1. Tax policy

Under a tax regime, rational emitters behave according to Equation (8), leading to abatement levels $a_{k}^{\tau}$. Notice that $\delta=0$. Since the policy maker relies solely on an emissions tax, there are no constraints on quantity, hence $A=0$. Thus, the tax rate $\tau=\bar{\tau}$ has to be fixed such that the expected aggregate abatement level complies with the environmental target (see Equation (4)). Thus, we have

$$
\pi \sum_{k=1}^{K} N_{k} a_{k}^{\bar{\tau}}=\gamma E
$$

2. Abatement subsidies

Again, the policy maker introduces a price incentive to subsidize abatement. In this case, Equation (8) is valid for $\delta=1$. The subsidy rate has to be chosen such that Equation (16) is met.

3. Direct abatement regulation

In this case, the regulatory authority does not rely on prices. Instead, it fixes an abatement standard $A>0$ with which each emitting firm has to comply. Thus, all firms will abate according to this provision irrespective of their behavioural type. The standard $A=\bar{A}$ must be set such that the environmental target is achieved, i.e.,

$$
\bar{A} \sum_{i=1}^{K} N_{k}=\gamma E
$$

From the traditional model, we know that a price setting policy always guarantees that the environmental target will be achieved in an efficient way, provided the emission price level is set properly. In contrast to this, introducing a mandatory abatement level is inefficient as it leads to higher aggregated abatement costs than in the case of a tax/subsidy-approach. At this point, it is interesting to analyse whether this assessment applies also in a world where emitters display heterogeneous behaviour.

\section{Result 1.}

- In the case of behavioral heterogeneity, the tax/subsidy rate must be higher than in the case of a pure price-standard approach, i.e., $\bar{\tau}>\tau^{*}$.

- A price oriented policy is not always better than a quantity-setting regulation. The relative performance depends on technological properties, the distribution of technology classes and the proportion of rational firms.

Proof. The first part follows directly by comparing Equation (9) with Equation (16). The second part will be shown by example in Section 2.3 below.

Obviously, if a certain proportion of firms is price resistant, a tax policy can only achieve the abatement target if the tax rate is higher than in the classical price standard approach case. This inertia calls for the use of an additional instrument, namely, the green defaults to be introduced in the following section.

\subsection{Green Defaults as Optimal Policy Mix}

We have assumed that a certain proportion of emitters do not actively choose their emission levels by minimizing their abatement costs. One remedy against this inertia could be a command 
and control-style quantity regulation which forces all emitters to achieve a certain level of abatement irrespective of their abatement costs. Of course, this type of policy only achieves the environmental goal at high abatement costs. Another more flexible governance option is to introduce green defaults. In our model, a green default is a communicated presetting of a fixed abatement level emitters can comply with. In contrast to the traditional quantity constraint of a command and control policy, here emitters are allowed to deviate from the prescribed level if they wish to do so. The decision to deviate leads to additional costs (benefits) in terms of tax payments (subsidies). If the active emitter increases her abatement level beyond the default value, she receives subsidies; if she reduces her abatement efforts, she is required to pay tax. This decision is balanced against the rising (falling) abatement costs. This mechanism resembles the 'flexibility regulations' of the early U.S. Clean Air Act ('bubble' and 'offsets') but can also be seen in any standard-based rule, for example a speed limit, which gives rise to monetary sanctions, fines or liability, if the choice of speeding-and-paying can be modeled as a deliberate economic decision of the agent In the more general terms of nudging, it would be any behavioral standard which preserves the choice of disobedience (over-obedience) with the consequence of additional psychological or situational economic costs (benefits) such as the 'costs' of changing TV settings from energy-saving to time-saving stand-by modes or the 'benefits' of having healthy foods within arms reach.

To capture this mechanism in the model, we rewrite Equation (8) as follows:

$$
\min _{a_{k}}\left[C_{k}\left(a_{k}\right)-\tau\left(a_{k}-A\right)\right] .
$$

As before, $\tau$ is a tax rate to be fixed and $A$ is the default value. The rational emitter of technology class $k$ minimizes total abatement costs leading to

$$
C_{k}^{\prime}\left(a_{k}\right)=\tau, \Rightarrow a_{k}^{\tau}, \quad k=\{1,2, \cdots, K\} .
$$

In contrast to rational firms, passive emitters will stick to the green default $A$ as preset and communicated. A policy signal $A=0$ will be similarly understood by passive firms as a behavioral anchor for uncontrolled emissions. Having thus described the behavior of all emitting firms, we can now proceed to the task the policy maker has to solve.

As in the traditional policy setting, the task consists of choosing the policy that minimizes aggregate abatement costs. Since emission behaviour is random, the relevant object function is expected aggregate abatement costs derived in Equation (15). In contrast to the traditional setting, the policy maker does not choose between a price or a quantity approach but instead seeks to utilize both instruments. Thus, green nudging can be modeled as the application of a policy mix approach consisting of prices (taxes/subsidies) and quantities (green defaults). The rational emitters are incentivized by a tax/subsidy whereas the inert actors are led by the green default. Hence, the regulator needs these two instruments. Notice thereby that the regulator cannot infer the technology type of inert emitters from the observable abatement level, which is identical to the default. Hence, the regulator is not able to introduce green defaults depending on technological types $b_{k}$ but instead has to confine himself to only one green default applying to all technologies. This informational limitation prevents the regulation scheme to achieve the first best allocation, i.e., the cost minimal allocation of the price-standard approach.

Minimizing aggregate expected abatement costs Equation (15) subject to the environmental constraint

$$
\pi \sum_{k=1}^{K} N_{k} a_{k}^{\tau}+(1-\pi) \sum_{k=1}^{K} N_{k} A \geq \gamma E
$$

leads to the following first order conditions which are also sufficient to characterize the optimal policy due to the assumed properties of the abatement cost functions: 


$$
\begin{aligned}
\pi \sum_{k=1}^{K} N_{k}\left(C_{k}^{\prime}\left(a_{k}^{\tau}\right)-\lambda\right) \frac{\partial a_{k}^{\tau}}{\partial \tau}=0 \\
(1-\pi) \sum_{k=1}^{K} N_{k}\left(C_{k}^{\prime}(A)-\lambda\right)=0
\end{aligned}
$$

where $\lambda$ is the Lagrangean. Bearing in mind that $\frac{\partial a_{k}^{\tau}}{\partial \tau}>0$ and utilizing Equation (19) we can transform Equation (22) to

$$
\frac{\sum_{k=1}^{K} N_{k} C_{k}^{\prime}(A)}{\sum_{k=1}^{K} N_{k}}=\tau
$$

The green default should be set such that the average marginal abatement costs of all emitters is equated to the tax rate, which is in turn equal to the marginal abatement costs of rational firms. We call this optimality condition the average marginal abatement cost rule (AMAC). This rule is easily explained if one multiplies the nominator and the denominator by $(1-\pi)$ exhibiting the ratio as the average marginal abatement costs of passive firms. Since passive emitters do not exploit efficiency gains by equating their marginal abatement costs to the tax rate, the policy maker should set the green default such that these firms' average marginal abatement costs are equal to the marginal abatement costs of each rational firm.

Together with the environmental constraint Equation (20), the AMAC can be used to determine the optimal policy mix $\left\{\tau^{o}, A^{o}\right\}$ whose properties are summarized in the following proposition.

\section{Result 2.}

1. Optimality of policy mix: It is optimal to introduce a green default, i.e., a pure price policy approach is suboptimal. An exclusively quantity approach is likewise suboptimal. In formal terms:

$$
0<A^{o}<\frac{\gamma E}{(1-\pi) \sum_{k=1}^{N_{k}} N_{k}}
$$

2. The tax rate of the policy mix approach is higher than the tax rate of the price standard approach. Formally:

$$
\bar{\tau}>\tau^{0}>\tau^{*} .
$$

Hence, under a green default approach, every rational emitter will invest more in abatement than in the price standard approach case.

Proof. See Appendix A.

The first assertion simply states that both instruments should be utilized. Price responsive firms react to the tax rate and passive emitters follow the green default. Since aggregated abatement costs are to be minimized, both instruments are deployed such that the marginal abatement costs of both behavioral groups are equated, as stated by the average marginal abatement cost rule Equation (A2). Figure 1 illustrates this finding. The AMAC-rule is satisfied at the point $\left\{A_{0}, \tau^{0}\right\}$. From Figure 1 , one also can easily see that $\bar{\tau}>\tau^{0}$. In the pure tax approach, the tax rate $\bar{\tau}$ is chosen such that the abatement target $\gamma E$ is achieved (point $\mathrm{pT}$ ). The tax rate must be set rather high to meet this target. Aggregated abatement costs can be reduced by lifting the abatement level of passive emitters and thereby making it possible to reduce the tax rate.

The first part of the proposition and the tax relation $\bar{\tau}>\tau^{0}$ is easy to understand. This does not extend to the relation between $\tau^{0}$ and $\tau^{*}$, which follows from the AMAC-rule and the convexity of the 
abatement cost curve. The proof contained in the appendix shows that, under the green default, the sum of abatement levels of rational firms is always higher than the sum of regulated abatements of the passive emitters, i.e.,

$$
\sum_{k=1}^{K} N_{k} a_{k}^{\tau^{o}}>\sum_{k=1}^{K} N_{k} A^{o} .
$$

Inserting this relation into Equation (20) immediately yields the result that the tax rate $\tau^{0}$ would lead to higher total abatement efforts than required in the price-standard approach of Baumol and Oates (see Equation (9)), i.e.,

$$
\sum_{k=1}^{K} N_{k} a_{k}^{\tau^{0}}>\gamma E .
$$

It is interesting to observe that the presence of passive emitters $(\pi<1)$ requires a higher tax rate on emissions than in the classical price standard approach despite the introduction of a green default that secures the abatement by passive emitters. Passive emitters effectively cause an externality in terms of more burdensome regulation for their active counterparts.

\section{Corollary 1.}

- The strictness of environmental policy decreases (increases) with the fraction of rational (passive) emitters. In formal terms:

$$
\frac{\partial \tau^{o}}{\partial \pi}<0 \text { and } \frac{\partial A^{o}}{\partial \pi}<0 .
$$

- Aggregated abatement costs decrease as the proportion of price responsive firms increases, i.e.,

$$
\frac{\partial A A C}{\partial \pi}<0 .
$$

Proof. See Appendix A.

This corollary re-emphasizes the findings of result 2 by following the optimal policy trajectory with respect to the fraction of rational firms. Starting from the price-standard approach case $\pi=1$, it becomes clear that environmental policy must be strengthened. Both the tax rate and the green default must be increased as $\pi$ decreases in order to guarantee the environmental target $\gamma E$. The larger the fraction of passive emitters, the higher the green standard and, at the same time, the higher the tax rate.

The fraction of passive emitters can be seen as a measure of the rigidity of markets. More rigid markets demand stronger regulatory interventions. In the case of pure taxes, regulators need to consider that some passive parties can not be moved by taxes. They will have to adopt higher taxes for rationally acting emitters to achieve the overall desired level of abatement.

The impact on aggregate abatement costs (see Equation (15)) is also rather obvious. The larger the fraction of rational firms minimizing their abatement costs, the lower aggregate abatement costs are.

\subsection{Example: Two Technology Classes}

The results obtained can be exemplified for the case of two technolgies $b_{1}<b_{2}$ and $N_{1}=N_{2}$ emitters within each technology class, where $b_{1}=1, b_{2}=4, \pi=0.5, \gamma E=80$ and $N_{1}=N_{2}=1$. Utilizing the abatement cost function Equation (2), we can derive from Equation (19) the optimal abatement efforts of rational emitters

$$
a_{k}^{\tau}=\frac{\tau}{b_{k}}, \quad k=1,2
$$


Inserting Equation (30) into Equation (20) establishes the default value $A$ as a function of $\tau$ such that the emissions standard $\gamma E$ is met. In the following figure the emissions restriction is represented by the blue line.

Similarly, we can draw iso-abatement-costs curves by utilizing Equation (15). Iso-abatement cost curves can be obtained by inserting Equation (30) into Equation (15) for a predefined cost level CC. The red curve gives the iso-abatement cost curve for the cost level which relates to the optimal solution characterized by Equation (20) and Equation (23). Iso-abatement curves to the southwest (northeast) represent lower (higher) costs. The optimal policy mix $\left\{t^{0}, A^{o}\right\}$ is located where the slopes of both curves are equated. Figure 1 also enables us to demonstrate the findings of Result 1 . A pure tax policy approach, i.e. $\tau=\bar{\tau}$ (see Equation (16)), leads to a tax rate that is higher than the optimal tax rate. Vice versa, the abatement provision given by the pure command and control approach, i.e. $A$ is such that $(1-\pi) \sum_{k=1}^{K} N_{k} A=\gamma E$ (see Equation (17)), is higher than the green default $A^{o}$. Needless to say, points $(\mathrm{pT})$ and $(\mathrm{CaC})$ lead to higher aggregate abatement costs than under the optimal policy mix.

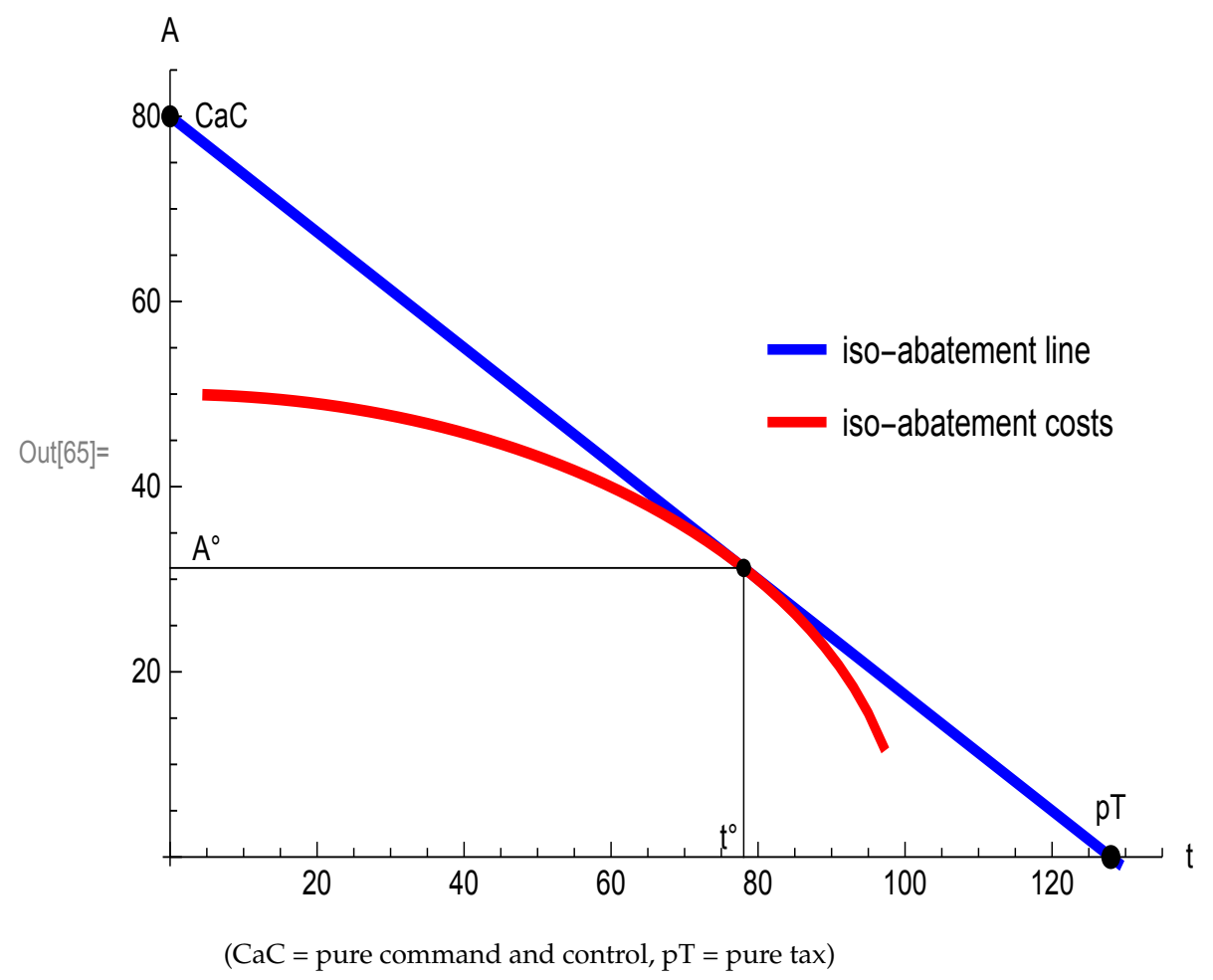

Figure 1. Optimal policy.

Whether $\mathrm{pT}$ or $\mathrm{CaC}$ leads to higher aggregate abatement costs (see Result 1 ) has yet to be evaluated. In the following Figure 2, we have drawn total abatement costs for the pure tax case (orange surface) and for the command-and-control approach (blue surface).

The orange surface is obtained by inserting the pure tax policy approach into the sum of both abatement cost functions. From Equation (16), we obtain

$$
a_{1}^{\tau}+a_{2}^{\tau}=\left[\frac{1}{b_{1}}+\frac{1}{b_{2}}\right] \tau=\gamma E / \pi
$$

which can be solved for $\bar{\tau}$. Inserting $\bar{\tau}$ into the quadratic abatement cost function yields the total

$$
\pi\left[C_{1}\left(a_{1}^{\tau}\right)+C_{2}\left(a_{2}^{\tau}\right)\right]=\frac{(\gamma E)^{2} b_{1} b_{2}}{2 \pi\left(b_{1}+b_{2}\right)} .
$$


Abatement costs for passive emitters are nil, since $A=0$. They simply pay the full tax burden on their unreduced emissions baseline $\left(e_{i}^{\max }\right)$. Notice that in these partial equilibrium models, it is assumed that tax receipts are returned to the emitting industry sector on a lump-sum basis. Notice further that the aggregated abatement costs depend on technologies $\left(b_{i}\right)$ and on the proportion of rational emitters. The surface is drawn as a function of $b_{1}$ and $b_{2}$. Similarly, total abatement costs under a command and control approach can also be derived (blue surface). Utilizing the abatement cost functions and Equation (17), we get

$$
C_{1}(\bar{A})+C_{2}(\bar{A})=\frac{\left(b_{1}+b_{2}\right)}{2} \frac{(\gamma E)^{2}}{4} .
$$

Again, total costs are a function of $b_{1}$ and $b_{2}$.

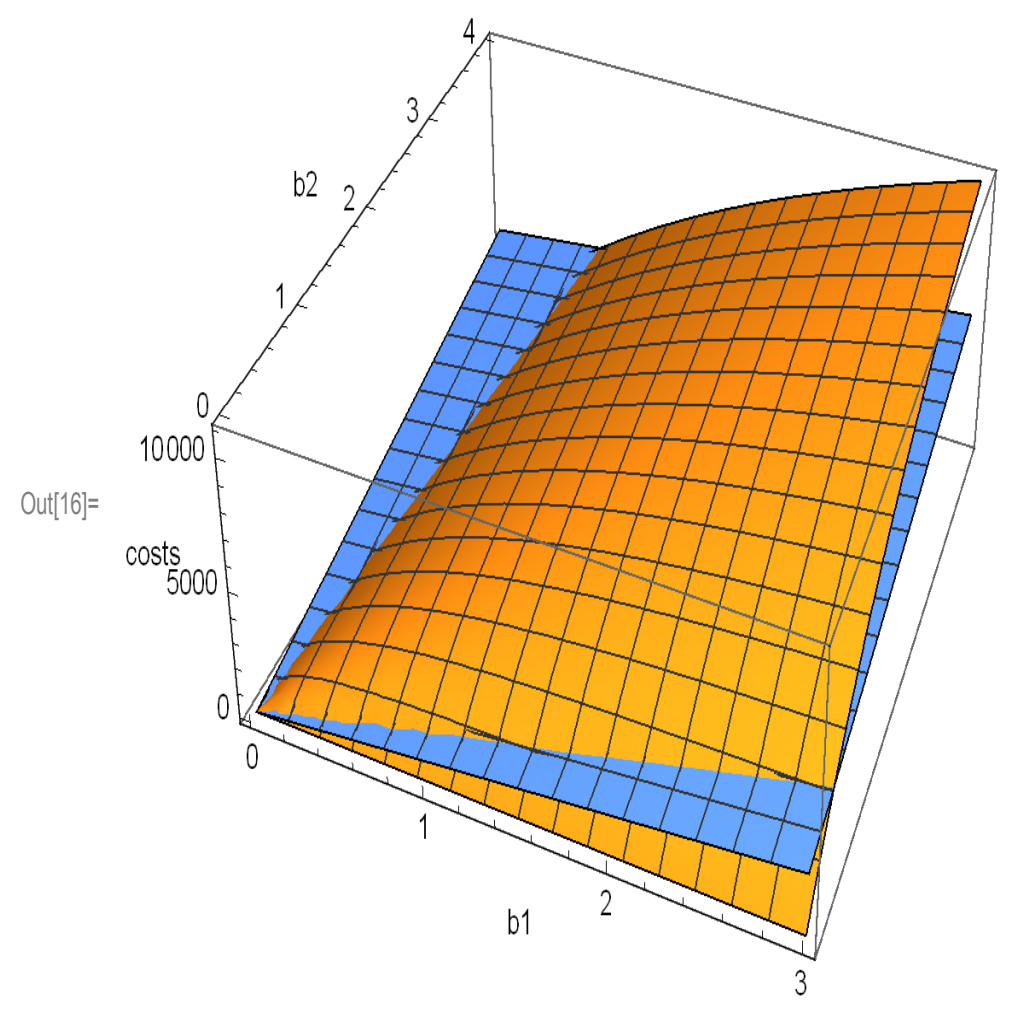

(orange surface $=$ costs under pure tax policy, blue surface $=$ costs under pure command and control)

Figure 2. A pure policy comparison.

The figure clearly shows that the success of both pure policies depends on the structure of technologies. If technologies are very diverse, i.e., if the absolute amount of the difference of $b_{1}-b_{2}$ is large, then the pure tax policy approach fares better than the command -and-control-approach, and vice versa. This result is easily understood. In the pure tax case, the tax rate must be rather high due to the fact that only a fraction of all emitters will respond. Hence, to fulfill the standard $\gamma E$, the policy must be fairly strict, leading to relatively high aggregate abatement costs due to the convexity of cost curves (Note that passive firms do not abate in the pure tax case). By contrast, an overall standard applied to all emitters can be relatively weak since all firms have to fulfill the provision $A$. However, this command and control approach is rather inefficient in the case of heterogeneous marginal abatement cost curves. Thus, there are two countervailing forces that affect total abatement costs under the two regulatory regimes. On the one hand, the pure tax approach is highly efficient but covers only the proportion of rational emitters. On the other hand, we have the command and control approach covering all emitters but inefficiently. The more technologies differ, the greater this inefficiency is. 
This can be seen by the area in the $b_{1}-b_{2}$ plane where aggregate abatement costs under a pure tax policy are higher than under the command and control approach decreases if the fraction of rational firms increases. If we equate Equation (32) and Equation (33) and solve for, say, $b_{2}$ we get the two solutions

$$
b_{21}=\frac{(2+\pi)+2 \sqrt{(1-\pi)}}{\pi} b_{1} \quad b_{22}=\frac{(2+\pi)-2 \sqrt{(1-\pi)}}{\pi} b_{1} .
$$

Both solutions are the mathematical expression of the cut lines of the hatched with the plain surface. If we derive Equation (34) with respect to $\pi$, we can observe that the slope of the left (right) solution for $b_{2}$ decreases (increases). If the fraction of rational firms increases (decreases), the set of $b_{1}-b_{2}$-combinations, where total abatement costs under a pure tax policy are higher than under a command and control approach, contracts (broadens). The implication is quite obvious. The more rational emitters there are, the more appropriate is a price-oriented policy approach and vice versa: the more passive firms exist, the more a command and control approach is appropriate.

In the remainder of the section, we analyze the case of the two emitters further by assuming that the behavioral probabilities depend on the abatement technologies. It is very plausible to assume that the probability of rational action increases with the abatement costs and vice versa. The stronger the consequences of the action, the more the actors will take care of it. In the context of the numerical example for two emitters, this implies

$$
b_{1}<b_{2} \Rightarrow \pi_{1}<\pi_{2}
$$

In order to investigate the implications of this correlation on the optimal policy mix, we extend the optimization approach to two different probabilities. Recalling that marginal abatement costs are $C_{k}^{\prime}(a)=b_{k} a$ and $a_{k}^{\tau}=\frac{\tau}{b_{k}}$ (see Equation (30)), it is straightforward to derive optimality conditions for the case of probabilities correlated with the abatement technology. Inserting $a_{k}^{\tau}$ and $C_{k}^{\prime}(a)$ into Equation (20) and Equation (23) for $N_{1}=N_{2}=1$ yields the following equations:

$$
\begin{aligned}
\pi_{1} a_{1}^{\tau}+\pi_{2} a_{2}^{\tau}+\left(\left(1-\pi_{1}\right)+\left(1-\pi_{2}\right)\right) A & =0, \\
\left(1-\pi_{1}\right) b_{1} A+\left(1-\pi_{2}\right) b_{2} A-\left(1-\pi_{1}\right) \tau-\left(1-\pi_{2}\right) \tau & =0 .
\end{aligned}
$$

These two equations can be solved for the optimal policy mix $\left\{\tau^{o}, A^{o}\right\}$. Both instruments depend on the various parameters $b_{i}$ and $\pi_{i}$. To analyze the correlation effect, we resume the numerical values of all parameters. In addition, we set $\pi_{1}=0.5$ and increase $\pi_{2}$ steadily in the interval $[0.5,1.0]$.

Figure 3 shows that the optimal tax is to be decreased while the optimal green default must be increased This result is plausible. The aggregated abatement costs for behavioral correlation are minimized if the green default for emitters with low abatement costs and comparatively high probability of inert behavior is increased. Conversely, the optimal emission tax is reduced because rational taxes have comparatively high abatement rates. Notice that for $p_{2}=0.5$, the optimal values are of course equal to the optimal values derived for the uncorrelated case $p_{1}=p_{2}=\pi=0.5$ (cp. Figure 1). Notice further that one must be careful with the interpretation of the result because it has only been derived in the context of a small numerical example. Further research is still needed here in order to achieve a robust result. 


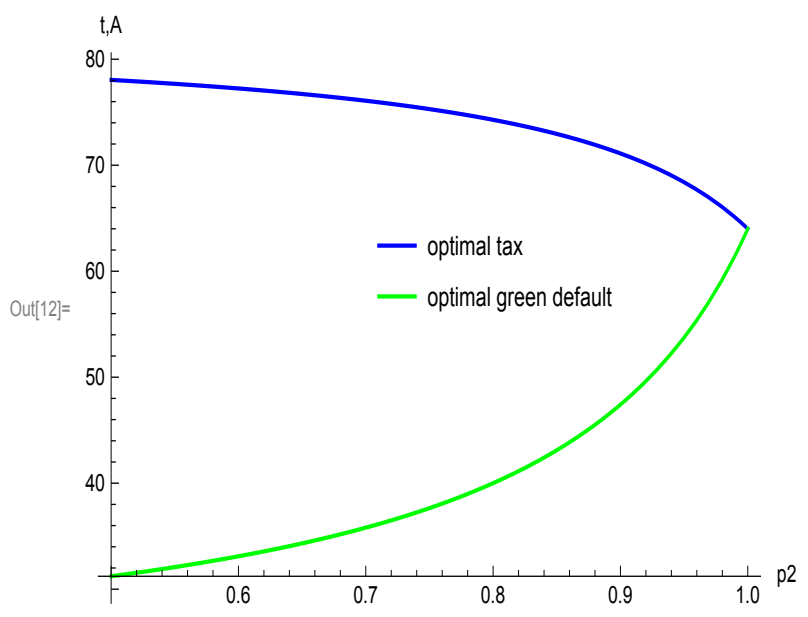

Figure 3. Correlation effect.

\section{Conclusions}

This paper has demonstrated that the existence of subpopulations with price resistant behaviour and trustful and overconfiding compliance with defaults has important implications for the design of environmental policy. Uniform command and control approaches can outperform price-based instruments, and pure tax/subsidy schemes need to be adjusted to achieve the politically desired level of total emissions. As a choice-preserving policy mix, green defaults are superior to any single-instrument policy in this case of behavioural heterogeneity. Much remains to be done. There are many empirical examples of the effectiveness of nudges in environmental policies, for example in policies to improve energy efficiency and the choice of green energy (Allcott et al. [28], Shogren et al. [34,35], Ferraro, Miranda and Price [36], Ebeling and Lotz [37]). However, most of the literature is concerned with individual and household environmental behaviour. Few studies have looked at organizational nudges despite pervasive evidence of managerial inattention and organizational routines (Sims [38]; Wiederholt [39]; Kaplan and Henderson [29], Duflo, Kremer and Robinson [40]). Such research could help reveal important factors that contribute to price inertia and anchoring decisions to defaults in firms. Additionally, the interplay of consumer inertia and dynamic pricing (Zhao et al. [41]) has so far not been sufficiently considered in the nudging literature. Time-variant pricing of energy usage, for example, would increase the difference in profits from behavioural inertia compared to rational choice and consequently reduce the probability of sticking to defaults within a population. The more general question arising from these analyses is how the fraction $\pi$ of behavioural inertia within a population could be reduced by means of tailored policy efforts. While environmental awareness raising and education could clearly contribute to a lower $\pi$ and thus to greater regulatory efficiency according to our findings, they would also involve additional costs of implementation. Consideration of these additional instrument costs and benefits as well as the remaining behavioural inertia may lead to even more policy mixing. Green defaults combined with any such instrument may prove superior to both traditional single-instrument policies (such as quotas and taxes) and stand-alone nudges. Finally, we would expect important insights to be gained from applying our theory of optimal nudging to different special cases. For example, empirical findings show that the default inclusion of natural hazards in general homeowners insurance makes a considerable difference in the uptake of natural hazards insurance compared to a rule of separation of both lines (Schwarze and Wagner [17]). Based on our theory of optimal defaults, we would expect that 'insurance nudging' is economically superior to mandatory insurance (with no choice-preserving mechanism) or direct regulation of private risk mitigation. Another promising area of study, following the recent findings of Parry et al. [42], would be to compare emissions standards (which allow a trade-off between activity level and technology choice) and technology fixes such as fuel efficiency standards for cars. 
Overall, price inertia and passivity in markets are a widely observed 'fact of economic life' as we know from nominal wage rigidity or asset price bubbles. Empirical behavioral approaches can help to explain these observations but also demonstrate a degree of learning from errors so that the efficiency loss from sticky behaviors seems to decline over time (List [43]). However, even in dynamic models of regulation with learning from mistakes, we would still expect the rule to hold that an instrument mix such as nudges will outperform any single instruments because heterogeneous populations will most probably be learning from mistakes at different speeds.

Author Contributions: This paper is to be attributed in equal parts to the authors.

Funding: This research was partly funded by the EU Framework Programme for Research and Innovation (H2020) under the Grant No. 653255 (PLACARD).

Conflicts of Interest: The authors declare no conflict of interest.

\section{Appendix A}

\section{Appendix A.1. Proof of Result 2}

To prove the first statement assume, per absurdum, that $A^{0}=0$. From Equation (23), it follows that $\tau^{o}=0$ and, hence, by Equation (19) that $a_{k}^{0}=0, \forall k$. However, this contradicts the environmental constraint Equation (20). Next, assume, per absurdum, that

$$
A^{o}=\frac{\gamma E}{(1-\pi) \sum_{k=1}^{N_{k}} N_{k}} .
$$

From the environmental constraint Equation (20), it follows that $\tau^{0}=0$ so as to reduce the abatement levels to zero, i.e., $a_{k}^{0}=0$. However, from Equation (23), it follows that $\tau^{0}>0$, which is a contradiction.

To prove the second statement, we utilize the assumed quadratic form of the abatement cost function (see Equation (2)). Utilizing Equation (19), AMAC can be rewritten as:

$$
\frac{\sum_{k=1}^{K} N_{k} b_{k} A}{\sum_{k=1}^{K} N_{k}}=\tau=b_{j} a_{j}^{\tau^{o}}, \forall j=\{1,2, \cdots, K\} .
$$

Multiplying both sides by $N_{j}$ and summing up leads to

$$
\sum_{k=1}^{K} N_{j} b_{j}\left(A^{o}-a_{j}^{\tau^{o}}\right)=0
$$

From Equation (A3), we can infer that there must be a $i \in\{1,2, \cdots, K\}$ such that $a_{i-1}^{\tau^{0}}>A$, $a_{i}^{\tau^{0}} \leq A^{o}$ and $a_{i+1}^{\tau^{0}}<A^{o}$. Equation (A3) can be rewritten as

$$
b_{i}\left(A^{o}-a_{i}^{\tau^{o}}\right)=-\sum_{k=1}^{i-1} N_{k} b_{k}\left(A^{o}-a_{k}^{\tau^{o}}\right)-\sum_{k=i+1}^{K} N_{k} b_{k}\left(A^{o}-a_{k}^{\tau^{o}}\right) .
$$

Adding to both sides $b_{i} \sum_{k \neq i}^{K} N_{k}\left(A^{o}-a_{k}^{\tau^{0}}\right)$ leads to

$$
b_{i} \sum_{k=1}^{K} N_{k}\left(A^{o}-a_{k}^{\tau^{o}}\right)=\sum_{k=1}^{i-1} N_{k}\left(b_{i}-b_{k}\right)\left(A^{o}-a_{k}^{\tau^{o}}\right)+\sum_{k=i+1}^{K} N_{k}\left(b_{i}-b_{k}\right)\left(A^{o}-a_{k}^{\tau^{o}}\right) .
$$

From the assumed properties of the abatement costs function and from Equation (8), we know that

$$
\begin{aligned}
& b_{1}<b_{2}<\cdots<b_{K}, \\
& a_{1}^{\tau}>a_{2}^{\tau}>\cdots>a_{K}^{\tau} .
\end{aligned}
$$


Taking these properties into account, it follows from Equation (A5) that

$$
\sum_{k=1}^{K} N_{k}\left(A^{o}-a_{k}^{\tau^{o}}\right)<0 \Rightarrow \sum_{k=1}^{K} N_{k} a_{k}^{\tau^{o}}>\sum_{k=1}^{K} N_{k} A^{o} .
$$

Define the difference

$$
\epsilon=\sum_{k=1}^{K} N_{k} a_{k}^{\tau^{o}}-\sum_{k=1}^{K} N_{k} A^{o}>0 .
$$

Then, it follows from Equation (20),

$$
\sum_{k=1}^{K} N_{k} a_{k}^{\tau^{o}}=\gamma E+(1-\pi) \epsilon \Rightarrow \sum_{k=1}^{K} N_{k} a_{k}^{\tau^{o}}>\gamma E .
$$

Since $a_{k}^{\tau}$ is a positive monotone function with respect to $\tau$, a comparison of Equation (9) with Equation (A9) shows immediately that $\tau^{0}>\tau^{*}$.

Appendix A.1.1. Proof of Corollary 1

Differentiating Equation (20) and Equation (23) with respect to $\pi$ leads to

$$
\left(\begin{array}{cc}
-\sum_{k=1}^{K} N_{k} & \sum_{k=1}^{K} N_{k} C_{k}^{\prime \prime}(A) \\
\pi \sum_{k=1}^{K} N_{k} a_{k}^{\tau^{0}} & (1-\pi) \sum_{k=1}^{K} N_{k}
\end{array}\right)\left(\begin{array}{c}
\frac{\partial \tau^{0}}{\partial \pi} \\
\frac{\partial A^{0}}{\partial \pi}
\end{array}\right)=\left(\begin{array}{c}
0 \\
-\sum_{k=1}^{K} N_{k} a_{k}^{\tau^{0}}
\end{array}\right) .
$$

From Equation (A10), it is easy to calculate

$$
\frac{\partial \tau^{o}}{\partial \pi}=\frac{\left(\sum_{k=1}^{K} N_{k} a_{k}^{\tau^{o}}\right)\left(\sum_{k=1}^{K} N_{k} C_{k}^{\prime \prime}(A)\right)}{|\Sigma|}<0,
$$

and

$$
\frac{\partial A^{o}}{\partial \pi}=\frac{\left(\sum_{k=1}^{K} N_{k}\right)\left(\sum_{k=1}^{K} N_{k} C_{k}^{\prime \prime}(A)\right)}{|\Sigma|}<0,
$$

where the determinant of the system matrix is $|\Sigma|<0$.

The second part of the corollary can be proved by recalling Equation (15)

$$
A A C=\pi \sum_{k=1}^{K} N_{k} C_{k}\left(a_{k}^{\tau}\right)+(1-\pi) \sum_{k=1}^{K} N_{k} C_{k}(A) .
$$

Utilizing the envelope theorem, the derivative of AAC with respect to $\pi$ is

$$
\frac{\partial A A C}{\partial \pi}=\sum_{k=1}^{K} N_{k} C_{k}\left(a_{k}^{\tau}\right)-\sum_{k=1}^{K} N_{k} C_{k}(A)<0 .
$$

The sign follows from the AMAC-rule Equation (A2) and the cost minimizing behaviour of rational firms (see Equation (19)).

\section{References}

1. Lourenço, J.S.; Ciriolo, E.; Almeida, S.R.; Troussard, X. Behavioural Insights Applied to Policy (BIAP): European Report 2016 (EUR 27726 EN). 2016. Available online: http://publications.jrc.ec.europa.eu/ repository/bitstream/JRC100146/kjna27726enn_new.pdf (accessed on 11 July 2018).

2. European Economic and Social Committee. Opinion on 'Towards Applying Nudge Thinking to EU Policies'. 2017. Available online: https://www.eesc.europa.eu/en/our-work/opinions-informationreports/opinions/towards-applying-nudge-thinking-eu-policies (accessed on 11 July 2018). 
3. Piniewski, B.; Codagnone, C.; Osimo, D. Nudging Lifestyles for Better Health Outcomes: Crowsourced Data and Persuasive Technologies for Behavioural Change; Publication Office of the European Union: Luxembourg, 2011.

4. Oullier, O.; Sauneron, S. "Green Nudges": New Incentives for Ecological Behaviour. Centre d'Analyse Stratégique (CAS). 2011. Available online: http:/ / archives.strategie.gouv.fr/cas/en/system/files/2011-0309-na-216-nudgesvertsgb_0.pdf (accessed on 11 July 2018).

5. Council for the Environment and Infrastructure (Raad voor de Leefomgeving en Infrastructuur, Rli). Influencing Behaviour. More Effective Environmental Policy through Insight into Human Behaviour. 2014. Available online: en.rli.nl/publications/2014/advice/influencing-behaviour (accessed on 11 July 2018).

6. Organisation for Economic Co-operation and Development (OECD). Behavioral Economics and Environmental Policy Design. Project Description, Empirical Policy Analysis Unit. 2012. Available online: https:/ /www.oecd.org/ env/consumption-innovation/Behavioural\%20Economics\%20and\%20Environmental\%20Policy\%20Design.pdf (accessed on 11 July 2018).

7. Carlsson, F.; Johansson-Stenman, O. Behavioral Economics and Environmental Policy. Annu. Rev. Resour. Econ. 2012, 4, 75-99. [CrossRef]

8. Madrian, B.C.; Shea, D.F. The power of suggestion: Inertia in 401 (k) participation and savings behavior. Q. J. Econ. 2001, 116, 1149-1187. [CrossRef]

9. Carroll, G.D.; Choi, J.J.; Laibson, D.; Madrian, B.C.; Metrick, A. Optimal Defaults and Active Decisions. Q. J. Econ. 2009, 124, 1639-1674. [CrossRef] [PubMed]

10. Revell, A.; Blackburn, R. The business case for sustainability? An examination of small firms in the UK's construction and restaurant sectors. Bus. Strateg. Environ. 2007, 16, 404-420. [CrossRef]

11. Ellison, G. Bounded rationality in industrial organization. In Advances in Economics and Econometrics: Theory and Applications; Blundell, R., Newey, W., Persson, T., Eds.; Cambridge University Press: Cambridge, MA, USA, 2006; pp. 142-174.

12. Weitzmann, M. Price versus Quantities. Rev. Econ. Stud. 1974, 41, 477-491. [CrossRef]

13. Malik, A.S. Enforcement Costs and the Choice of Policy Instruments for Controlling Pollution. Econ. Inq. 1992, 30, 714-721. [CrossRef]

14. Jolls, C.; Sunstein, C.R.; Thaler, R. A Behavioral Approach to Law and Economics. Stanf. Law Rev. 1998, 50, 1471-1550. [CrossRef]

15. Thaler, R.H.; Sunstein, C.R. Nudge: Improving Decisions about Health, Wealth and Happiness; Penguin Books: New York, NY, USA, 2008.

16. Schubert, C. Green nudges: Do they work? Are they ethical? Ecol. Econ. 2017, 132, 329-342. [CrossRef]

17. Michalek, G.; Meran, G.; Schwarze, R.; Yildiz, Ö. Nudging as a new "soft" tool in environmental policy-An analysis based on insights from cognitive and social psychology. Zeitschrift fuer Umweltpolitik 2016, 3, $43-81$.

18. Alcott, H. Social norms and energy conservation. J. Public Econ. 2011, 95, 1082-1095. [CrossRef]

19. Thaler, R.H.; Sunstein, C.R. Libertarian paternalism. Am. Econ. Rev. 2003, 93, 175-179. [CrossRef]

20. Camerer, C.; Issacharoff, S.; Loewenstein, G.; O’Donoghue, T.; Rabin, M. Regulation for conservatives: Behavioral economics and the case for "asymmetric paternalism". Univ. Pa. Law Rev. 2003, 151, 1211-1254. [CrossRef]

21. Hausman, D.M.; Welch, B. Debate: To nudge or not to nudge. J. Political Philos. 2010, 18, 123-136. [CrossRef]

22. Amir, O.; Lobel, O. Stumble, Predict, Nudge: How Behavioral Economics Informs Law and Policy. Columbia Law Rev. 2008, 108, 72-88.

23. Loewenstein, G.; Haisley, E. The economicst as therapist. Methodological ramifications of 'light' paternalism. In The Foundations of Positive and Normative Economics. A Handbook; Caplin, A., Schotter, A., Eds.; Oxford University Press: Oxford, UK, 2008; pp. 210-248.

24. Schnellenbach, J. Nudges and norms: On the political economy of soft paternalism. Eur. J. Political Econ. 2012, 28, 266-277. [CrossRef]

25. Croson, R.; Treich, N. Behavioral Environmental Economics: Promises and Challenges. Environ. Resour. Econ. 2014, 58, 335-351. [CrossRef]

26. Hansen, P.G.; Jespersen, A.M. Nudge and the manipulation of choice: A framework for the responsible use of the nudge approach to behaviour change in public policy. Eur. J. Risk Regul. 2013, 4, 3-28. [CrossRef]

27. Baumol, W.J.; Oates, W.E. The Use of Standards and Prices for Protection of the Environment. Swed. J. Econ. 1971, 73, 42-54. [CrossRef] 
28. Alcott, H.; Mullainathan, S.; Taubinsky, D. Energy policy with externalities and internalities. J. Public Econ. 2014, 112, 72-88. [CrossRef]

29. Kaplan, S.; Henderson, R. Inertia and incentives: Bridging organizational economics and organizational theory. Organ. Sci. 2005, 16, 509-521. [CrossRef]

30. Laffont, J.J.; Tirole, J. A Theory of Incentives in Procurement and Regulation; The MIT Press: Cambridge, MA, USA, 1993.

31. Dasgupta, P.; Hammond, P.; Maskin, E. On imperfect information and optimal pollution control. Rev. Econ. Stud. 1980, 47, 857-860. [CrossRef]

32. Spulber, D.F. Optimal environmental regulation under asymmetric information. J. Public Econ. 1988, 35, $163-181$. [CrossRef]

33. Mood, A.M.; Graybill, F.A.; Boes, D.C. Introduction to the Theory of Statistics, 3rd ed.; McGraw-Hill: Kogakusha, Tokyo, 1974.

34. Shogren, J.F.; Taylor, L.O. On Behavioral-Environmental Economics. Rev. Environ. Econ. Policy 2008, 2, $26-44$. [CrossRef]

35. Shogren, J.F.; Parkhurst, G.M.; Banerjee, P. Two Cheers and a Qualm for Behavioral Environmental Economics. Environ. Resour. Econ. 2010, 46, 235-247. [CrossRef]

36. Ferraro, P.J.; Miranda, J.J.; Price, M.K. The persistence of treatment effects with norm-based policy instruments: Evidence from a randomized environmental policy experiment. Am. Econ. Rev. 2011, 101, 318-322. [CrossRef]

37. Ebeling, F.; Lotz, S. Domestic uptake of green energy promoted by opt-out tariffs. Nat. Clim. Chang. 2015, 5, 868-871. [CrossRef]

38. Sims, C.A. Rational Inattention: A Research Agenda; Technical Report, Forschungszentrum der Deutschen Bundesbank, Discussion Paper No. 34; Deutsche Bundesbank: Frankfurt, Germany, 2005.

39. Wiederholt, M. Rational Inattention. In The New Palgrave Dictionary of Economics, Online ed.; Durlauf, S.N., Blume, L.E., Eds.; Palgrave Macmillan: London, UK, 2010.

40. Duflo, E.; Kremer, M.; Robinson, J. Nudging farmers to use fertilizer: Theory and experimental evidence from Kenya. Am. Econ. Rev. 2011, 101, 2350-2390. [CrossRef]

41. Zhao, L.; Tian, P.; Li, X. Dynamic pricing in the presence of consumer inertia. Omega 2012, 40, 137-148. [CrossRef]

42. Parry, I.W.; Evans, D.; Oates, W.E. Are energy efficiency standards justified? J. Environ. Econ. Manag. 2014, 67, 104-125. [CrossRef]

43. List, J.A. Does market experience eliminate market anomalies? Q. J. Econ. 2003, 118, 41-71. [CrossRef]

(c) 2018 by the authors. Licensee MDPI, Basel, Switzerland. This article is an open access article distributed under the terms and conditions of the Creative Commons Attribution (CC BY) license (http://creativecommons.org/licenses/by/4.0/). 